\title{
Experimental analysis of particle breakage and powder morphology in foam spray drying
}

\section{Lewandowski, A. ${ }^{\text {; }}$ Jaskulski, M. ${ }^{\text {a* }}$; Zbiciński, I. ${ }^{\text {a }}$}

a Faculty of Process and Environmental Engineering, Lodz University of Technology, Wolczanska Str 213., 95-924 Lodz, Poland.

*E-mail of the corresponding author: maciej.jaskulski@p.lodz.pl

\begin{abstract}
The paper presents results of experiments of gas admixing foam spray drying of maltodextrin in co-current spray tower. Significant effect of feed foaming on particle sphericity, angle of repose, apparent and bulk density, Hausner ratio and porosity was found. Number of broken particles achieved $60 \%$ for high foaming gas rate (GLR) and inlet air temperature due to particle overheating and bubble expansion. Analysis of the experiments results allowed to determine optimal range of operating conditions to reduce number of damaged particles, to around $15 \%$ for the highest GLR and to minimize product degradation.
\end{abstract}

Keywords: foamed materials, gas admixing, powder properties, powder quality 


\section{Introduction}

Standard spray drying process can be modified by foaming of feed solution. This technique, called "foam spray drying", can be carried out in two ways: by gas desorption or gas admixing method [1]. In gas desorption process, the feed is foamed due to the bubbles nucleation inside supersaturated droplets after atomization. In gas admixing method, foaming gas is directly injected into the slurry before spraying [2]. Powders obtained after foam spray drying are characterized by lower bulk density, higher porosity and particle sizes, better solubility and wettability than from conventional spray drying. Bubbles trapped in the particles during foaming can expand or deflect during drying producing hollow, spherical or damaged particles.

Properties and quality of powders in foam spray drying results from type of dried material, hydrodynamics of continuous and dispersed phase and operating process parameters $[3,4]$. Concentration of solid, type of solvent and rheological properties of feed effect particle shape and morphology [5]. Hollow particles are produced from "skin-forming" materials whereas porous and irregular particles are developed from suspensions or colloids [6,7]. In co-current flow of phases agglomeration hardly occur as particle collisions are rare. In counter-current or mixed phase flow, due to intensive air recirculation in drying chamber, particles collide frequently and agglomerate which increases average particle size in the final product [8]. Agglomeration can be also stimulated by the configuration of the nozzles or by the returning of the smallest fractions of particles into the atomization zone. Parameters of spray drying process like feed rate, air flow rate and temperature, air humidity effect drying rate and the final powder properties, e.g. improperly selected will result in particle cracking and degradation due to overheating.

The aim of this paper was to determine optimal parameters of foam spray drying process to produce high quality powders.

\section{Materials and Methods}

\subsection{Spray drying measurement system}

Co-current foam spray drying experiments were carried out in spray drying tower at Lodz University of Technology [2]. Drying air was filtered and then heated up by the electrical heaters with power $62 \mathrm{~kW}$. To reduce heat losses to the ambient air, the tower was insulated with the $40 \mathrm{~mm}$ layer of glass wool. Feed from thermostated tank was pumped to the top of the dryer, foamed and atomized by pressure nozzle. Dry powder was collected from the set of cyclones installed at the dryer bottom. 


\subsection{Foaming system}

Gas admixing foaming system consisting of a static mixer and capilarry dispensing gas to the solution and high speed homogenizer was installed at the top of the dryer.

Feed, foamed with nitrogen, was atoimzed by pressure nozzle LN-1 (Spraying. System Co., USA). The nozzle operates with pressure up to $3.0 \mathrm{MPa}$ with spray angle up to $70^{\circ}$ which reduce powder deposition on the column wall. Initial density and mass flow rate of feed were measured using Coriolis flow meter (Micro-Motion 2400S, Emerson, USA). All parameters wereregistered using data acquisition system (National Instruments, USA).

\subsection{Materials}

As a particle crust material maltodextrin DE12 (Nowamyl S.A, Poland) was used in all experiments. Uniform bubble diameters distribution in the emulsion was obtained applying Tween ${ }^{\circledR} 80$ produced by Croda International (UK).

\subsection{Experiments conditions}

Foam spray drying experiments were carried out for two initial maltodextrin DE12 concentrations $20 \%$ and $35 \%$, constant mass flow rate of feed, $14 \mathrm{~kg} / \mathrm{h}$, four initial air temperatures $150^{\circ} \mathrm{C}, 175^{\circ} \mathrm{C}, 200^{\circ} \mathrm{C}$ and $215^{\circ} \mathrm{C}$, for mass flow rate of foaming gas from 0.01 to $0.09 \mathrm{~kg} / \mathrm{h}$. Additional spray drying test without foaming of feed was carried out as reference case.

\section{Measurements results}

Samples of dry powder were collected and analyzed to determine particle size distribution (PSD), sphericity, angle of repose, apparent and bulk density, Hausner ratio and porosity.

PSD and particle shape were found from the analysis of images taken from the optical microscope OE4 (PZO, Poland) connected to Nikon E4500 camera with support of ImagePro Plus software (Media Cybernetics Inc., USA). At least 1000 particles per sample were analyzed to obtain representative results of powder morphology. Apparent density of the product was found with application of helium pycnometer AccPyc TC Micromeritics (USA). Bulk density of the powder was determined according to polish standard PN-80/C04532 whereas angle of repose following polish standard PN-89/C-04840. HR - Hausner ratio was calculated from relation bulk/tapped density.

Examples of selected results of particle morphology are presented in Fig. 1 to 3. Average particle sphericity $\left(\Psi_{\mathrm{k}}\right)$ for two different initial MDX concentrations $(20 \%$ and $35 \%)$ and for different drying gas temperatures as a function of gas-liquid ratio (GLR) are shown in Fig. 1. 

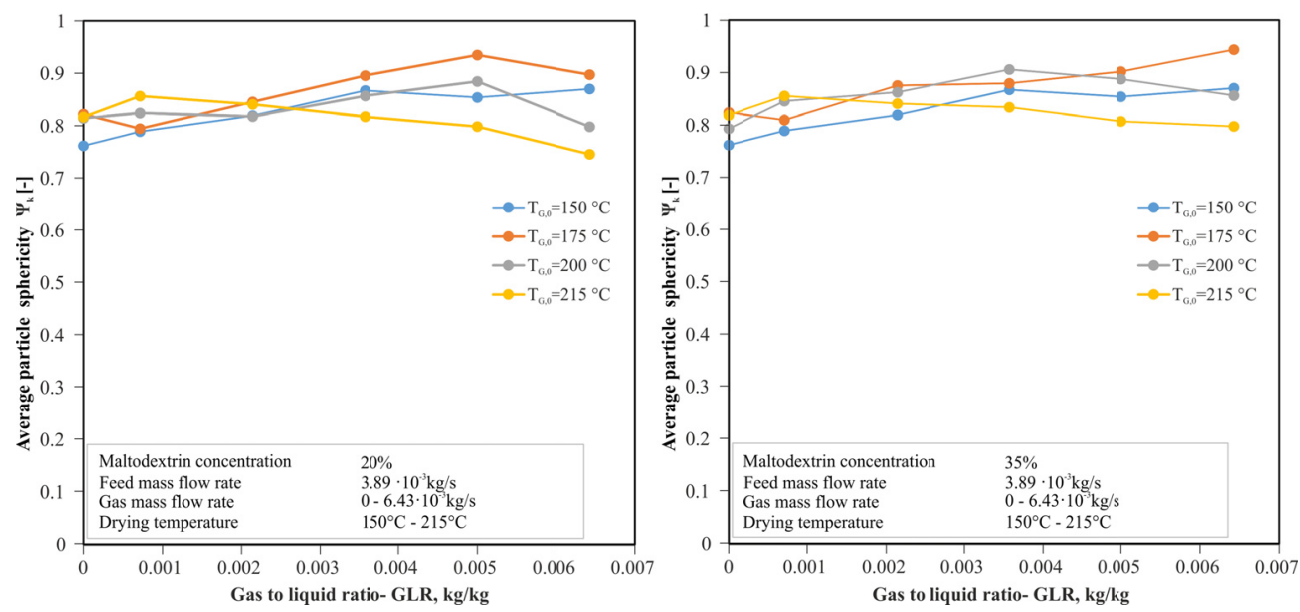

Fig. 1 Average sphericity of particles in collected powders.

Analysis of Fig. 1 shows that number of fully spherical particles increases with increasing of GLR. For the highest GLR and highest inlet air temperature $\left(\mathrm{T}_{\mathrm{G}, 0}=215^{\circ} \mathrm{C}\right)$ particles sphericity decreases to 0.7 and 0.8 which is a result of particles breakage due to high thermal expansion of the bubbles.

Table 1 shows average Sauter diameter of particles in the product for different GLR and gas temperatures. We can observe increase of average Sauter diameter with increasing of GLR due to thermal expansion of the gas bubbles. Slight effect of initial gas temperature on average Sauter diameter was found.

For highest GLR and high initial gas temperature increased number of smaller particles was observed as a results of particles breakage in the product.

Table 1. Average Sauter diameter of particles in the product.

\begin{tabular}{ccccc}
\hline Gas to liquid & \multicolumn{4}{c}{ Average Sauter diameter, $\boldsymbol{\mu m}$} \\
ratio- GLR & $\mathbf{T}_{\mathbf{G , 0},}=\mathbf{1 5 0}^{\circ} \mathbf{C}$ & $\mathbf{T}_{\mathbf{G}, \mathbf{0}}=\mathbf{1 7 5}^{\circ} \mathbf{C}$ & $\mathbf{T}_{\mathbf{G , 0}}=\mathbf{2 0 0}^{\circ} \mathbf{C}$ & $\mathbf{T}_{\mathbf{G , 0}}=\mathbf{2 1 5}^{\circ} \mathbf{C}$ \\
\hline $7.14 \cdot 10^{-4}$ & 52.96 & 52.98 & 51.84 & 51.91 \\
$2.14 \cdot 10^{-3}$ & 55.82 & 55.05 & 55.22 & 51.07 \\
$3.57 \cdot 10^{-3}$ & 54.82 & 58.05 & 58.00 & 55.80 \\
$5.00 \cdot 10^{-3}$ & 59.82 & 59.71 & 55.94 & 55.07 \\
$6.43 \cdot 10^{-3}$ & 57.72 & 61.91 & 56.62 & 57.06 \\
\hline
\end{tabular}


Fig. 2 displays selected morphological properties of the powders: apparent and bulk density, porosity and Hausner ratio and angle of repose as a function of GLR. Analysis of results presented in Fig. 2 shows significant effect of feed foaming on final powder properties.
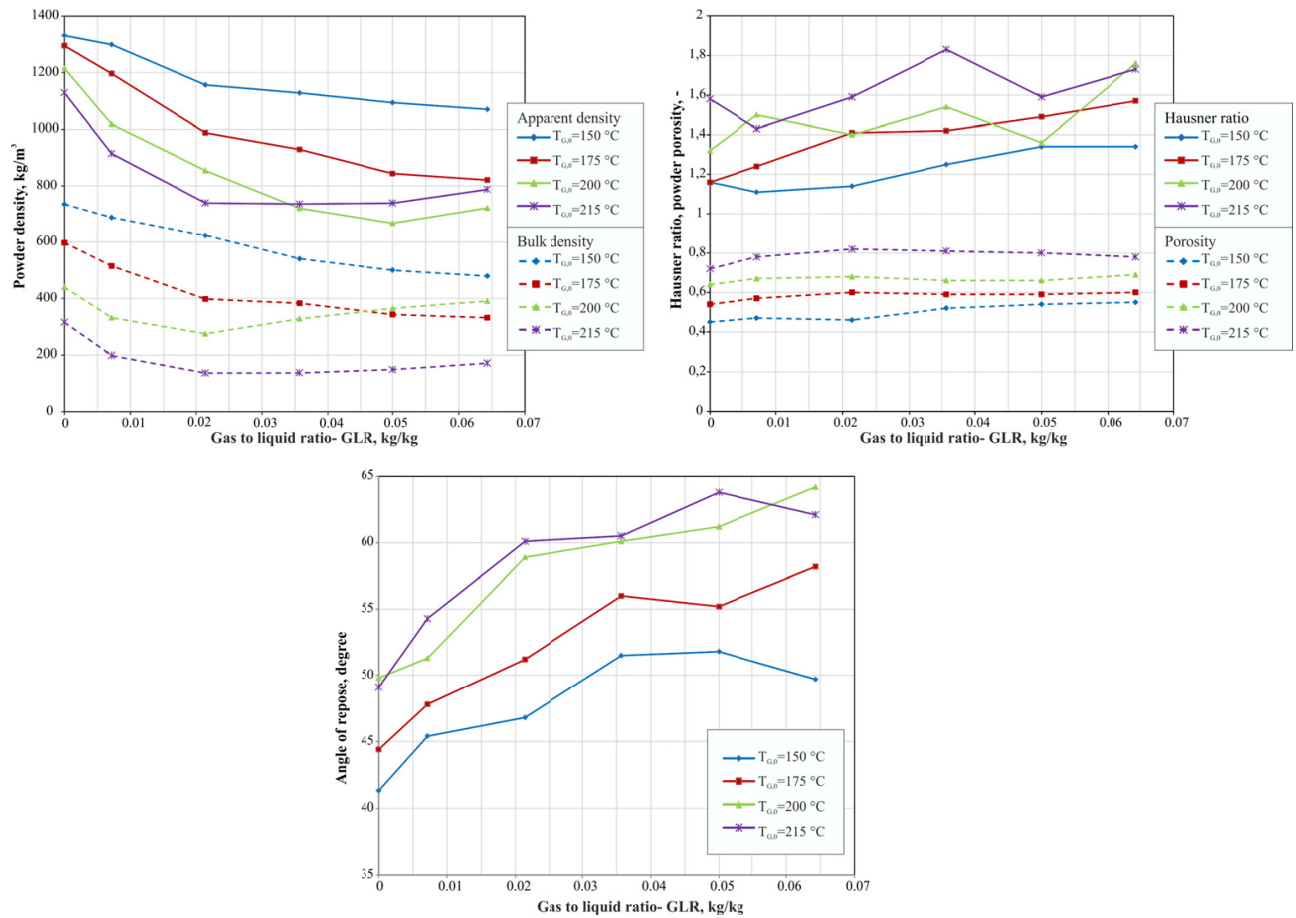

Fig. 2 Morphological properties of the powders.

We observe almost twofold decrease of bulk density of foamed materials in relation to nonfoamed feed. Angle of repose and Hausner ratio are growing with increasing of foaming gas flow rate (GLR) and initial temperature of drying air. Flowability of the powder changed from flowable (HR around 1.1) to cohesive (HR above 1.3). For the highest GLR (over $5.00 \cdot 10^{-3}$ ) and air inlet temperature above $200^{\circ} \mathrm{C}$, increase of bulk and apparent density is observed which is a result of filling of free spaces between the particles in the product by fragmented particles. Similar conclusions can be drawn from Fig. 1, where sphericity of particles decreases to $\Psi_{k}<0.8$ with increasing of GLR which indicates particle breakage.

Fig. 3 presents experimentally determined ratio between number of broken and undamaged particles as a function of foaming gas flow rate, GLR, for different initial maltodekstrin concentrations. 

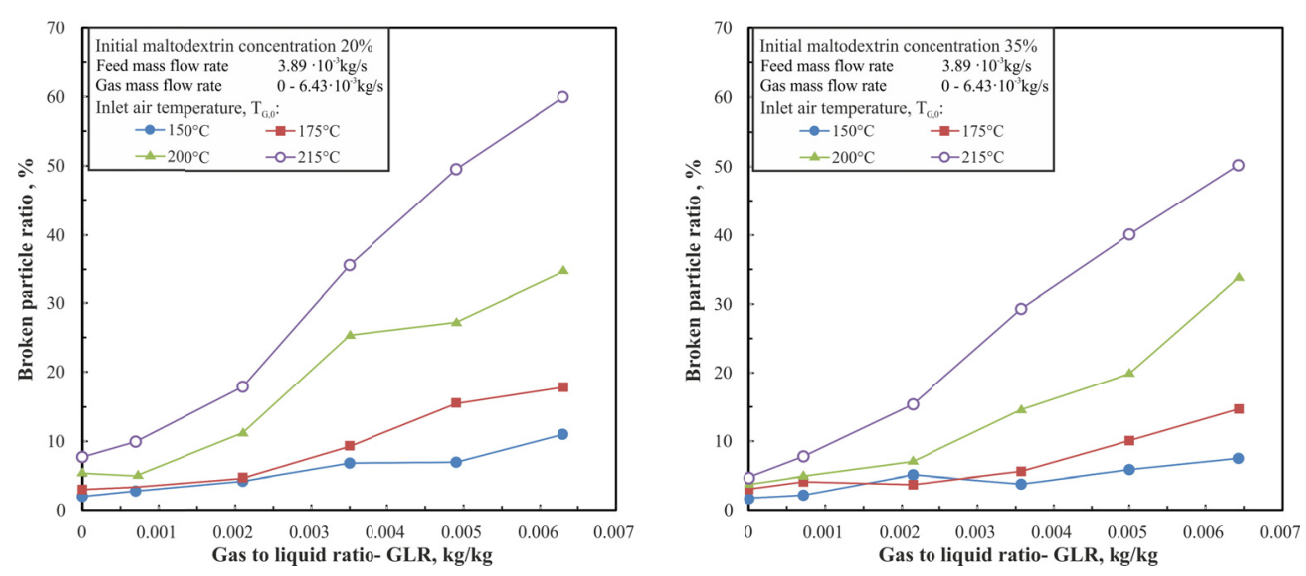

Fig. 3 Broken particle ratio of powder obtained from foamed spray drying experiments for different operating conditions.

Number of broken particles dramatically increases with GLR and inlet air temperature. For GLR above $0.006 \mathrm{~kg} / \mathrm{kg}$ and the highest drying air temperature, amount of broken particles in the product varies from 5\% to 50-60\% due to particle overheating and bubblle expansion. Proper selection of foam spray drying process parameters allow to reduce significantly number of damaged particles, to around $15 \%$ even for the highest GLR.

\section{Conclusions}

Co-current gas admixing foam spray drying tests was carried out in pilot-plant tower to determine physical and morphological properties of maltodextrine powder. Significant effect of feed foaming on sphericity, particle size distribution, angle of repose, apparent and bulk density, Hausner ratio and porosity of the powder was found.

Increase of a number of large and hollow particles with high sphericity and low bulk density, change of Hausner ratio from flowable (HR around 1.1) to cohesive (HR above 1.3) with increase of GLR was found.

For the highest GLR and air inlet temperature above $200^{\circ} \mathrm{C}$ an increase of bulk and apparent density was observed due to product degradation and fragmentation of particles as a result of high thermal expansion of bubbles.

Number of damaged particles can be significantly reduced, to around $15 \%$ for the highest GLR for properly selected operational foam spray drying process parameters. 


\section{Nomenclature}

$\begin{array}{cll}\text { GLR } & \text { gas/liquid ratio } & \mathrm{kgkg}^{-1} \\ \dot{\mathrm{m}} & \text { mass flow rate } & \mathrm{kgs}^{-1} \\ \mathrm{~T} & \text { temperature } & { }^{\circ} \mathrm{C}\end{array}$

Greek letters

$$
\Psi_{\mathrm{k}} \quad \text { sphericity }
$$

Subscripts

$\begin{array}{ll}0 & \text { initial } \\ \mathrm{G} & \text { gas }\end{array}$

\section{References}

[1] R. W. Bell, F. P. Hanrahan, and B. H. Webb, "Foam Spray Drying, Methods of Making Readily Dispersible Nonfat Dry Milk,” J. Dairy Sci., vol. 46, no. 12, pp. 1352-1356, Dec. 1963.

[2] I. Zbicinski and J. Rabaeva, "Analysis of Gas Admixing Foam Spray-Drying Process," Dry. Technol., vol. 28, no. 1, pp. 103-110, Dec. 2009.

[3] E. Tsotsas, "Influence of Drying Kinetics on Particle Formation: A Personal Perspective,” Dry. Technol., vol. 30, no. 11-12, pp. 1167-1175, 2012.

[4] D. E. Walton and C. J. Mumford, "Spray Dried Products-Characterization of Particle Morphology,” Chem. Eng. Res. Des., vol. 77, no. 1, pp. 21-38, 1999.

[5] M. Nuzzo, A. Millqvist-Fureby, J. Sloth, and B. Bergenstahl, "Surface Composition and Morphology of Particles Dried Individually and by Spray Drying," Dry. Technol., vol. 33, no. 6, pp. 757-767, Apr. 2015.

[6] J. Sloth, K. Jørgensen, P. Bach, A. D. Jensen, S. Kiil, and K. Dam-Johansen, "Spray Drying of Suspensions for Pharma and Bio Products: Drying Kinetics and Morphology,” Ind. Eng. Chem. Res., vol. 48, no. 7, pp. 3657-3664, Apr. 2009.

[7] E. Lintingre, F. Lequeux, L. Talini, and N. Tsapis, "Control of particle morphology in the spray drying of colloidal suspensions," Soft Matter, vol. 12, no. 12, pp. 7435-7444, 2016.

[8] M. Piatkowski and I. Zbicinski, "Analysis of the mechanism of counter-current spray drying,” Transp Porous Med, vol. 66, pp. 89-101, 2007. 